Anna Drake teaches in the Department of Political Studies at Queen's University (Kingston, Canada). Her research focuses upon issues of inclusion and efficacy in deliberative democratic theory, particularly as deliberative democracy intersects with protest. She is currently examining issues of inclusion and contestation in the move from deliberative theory to practice through an analysis of deliberative mini-publics. Her work has been published in Les ateliers de l'éthique.

Allison McCulloch is Assistant Professor in the Department of Political Science at Brandon University, Canada, where she teaches in the fields of International Relations and Comparative Politics. Her research is focused on the institutional design of power-sharing practices after ethnic conflict, with a special emphasis on consociational theory. She is currently working on a book manuscript that compares the track records of consociationalism and centripetalism at facilitating political stability in deeply divided societies.

\title{
Contemporary Political Theory Annual Prize of $£ 500$ for an article published in volume 9, 2010
}

Contemporary Political Theory (2011) 10, 312. doi:10.1057/cpt.2011.21

We are delighted to announce that the Contemporary Political Theory Annual Prize for 2010 has been awarded to Dr Sara Rushing, Assistant Professor of Political Science at Montana State University, USA, for her article 'Preparing for Politics: Judith Butler's Ethical Dispositions', published in number 3 (August), pp. 284-303.

The judges were unanimous in their verdict, writing as follows:

The article offers an elegantly systematic, insightful and eloquently argued analysis of the relationship between the ethical and political in Butler's work. Its dual focus on what Rushing calls the ethical dispositions of generosity, humility and patience together with the politics of 'unsatisfaction' will help move critical discussions of Butler's understanding of politics in new directions. A real joy to read!

The judging panel was chaired by Professor Moya Lloyd, Loughborough University, UK, and supported by Professor Kenneth Paul Tan, Lew Kuan Yew School of Public Policy, National University of Singapore and Professor Paul Apostolidis, Whitman College, USA. 